\section{DNA damage in acute myeloid leukemia patients of Northern Mexico}

\author{
Martha I. Dávila-Rodríguez, ${ }^{1}$ \\ Elva I. Cortés-Gutiérrez, ${ }^{1}$ \\ Roberto Hernández-Valdés, ${ }^{2}$ \\ Karla Guzmán-Cortés, ${ }^{1}$ \\ Rosa E. De León-Cantú, ${ }^{1}$ \\ Ricardo M. Cerda-Flores, ${ }^{3}$ \\ Enrique Báez-De la Fuente ${ }^{2}$ \\ ${ }^{1}$ Genetics Department, Centro de \\ Investigación Biomédica del Noreste, \\ Instituto Mexicano del Seguro Social, \\ Monterrey, Nuevo León \\ ${ }^{2}$ Hematology Service, High Specialty \\ Medicine Unit No. 25, Instituto \\ Mexicano del Seguro Social, Monterrey, \\ Nuevo León \\ ${ }^{3}$ Nursing Faculty, Universidad \\ Autónoma de Nuevo León, Monterrey, \\ Nuevo León, Mexico
}

\begin{abstract}
The purpose of this study was to evaluate DNA damage in the whole genome of peripheral blood leukocytes from patients with acute myeloid leukemia (AML) compared with a control group using DNA breakage detection-fluorescent in situ hybridization (DBD-FISH). Our results suggest that the DNA damage detected in patients with newly diagnosed AML was similar to that observed for the controls; this might be explained by the stimulation of a repair pathway by the pathogenesis itself. These findings indicate that inhibiting the repair pathway could be proposed to enhance the efficacy of chemotherapy.
\end{abstract}

\section{Introduction}

Acute myeloid leukemia (AML) is a very heterogeneous disorder in which hemopoietic progenitor cells (blasts) lose their ability to differentiate normally and respond to normal regulators of proliferation. AML is the most common form of acute leukemia in adults, with a median age at diagnosis of $65-70$ years. ${ }^{1}$ The prognosis of patients with AML is poor. In patients younger than 60 years, the complete remission (CR) rate is $60-70 \%$, whereas the overall cure rate is only $35-40 \% .^{2,3}$ Elderly patients and those with adverse karyotypes exhibit a CR rate of $35-50 \%$ and a cure rate of $10 \%$ or less. ${ }^{2}$ This pathology is associated with genomic damage characterized by a variety of chromosomal and molecular changes, ${ }^{4}$ which can be useful for associations with pathogenesis, progression, and chemotherapy response or resistance. ${ }^{5}$ The few studies that assessed genomic damage in patients with leukemia used approaches such as the micronucleus (MN) technique, ${ }^{6,7}$ sister chromatid exchange (SCE), ${ }^{8-12}$ or the alkaline comet assay. ${ }^{13,14}$ The findings of those studies were contradictory. DNA damage in Mexican patients with AML has not been explored. Currently, the DNA breakage detection-fluorescent in situ hybridization (DBD-FISH) technique ex vivo that allows the quantification of single-stranded DNA breaks (SSBs) and alkali-labile sites in the whole genome or specific sequences. ${ }^{15}$

The purpose of this preliminary study was to evaluate DNA damage in the whole genome of peripheral blood leukocytes (PBL) from Mexican patients with newly diagnosed AML compared with a control group using DBD-FISH.

\section{Materials and Methods}

\section{Study population}

We enrolled patients with AML from the Unidad Medica de Alta Especialidad No. 25 (UMAE 25), Instituto Mexicano del Seguro Social (IMSS). The clinical diagnosis was based on the morphological characteristics of Wright-Giemsa-stained smears of bone marrow aspirates and on immune-phenotyping analyses of leukemic cells. Hematological data of peripheral blood reveled that all patients registered high percentage of leukemia blasts (67-96\%). Controls showed only normal leucocytes. The study participants were classified as newly diagnosed patients $[\mathrm{n}=22$; age (average \pm SD) $=41 \pm 18.87$ years (range 17-65 years)] and healthy volunteers, who served as controls $[n=13$; age $37 \pm 14.38$ years (range 19-64 years)].

Written informed consent was obtained from all patients. The protocol was approved by the Research and Ethics Committee of IMSS (R-2015-785-033).

\section{DBD-FISH technique}

DBD-FISH was performed in PBL samples from patients and controls. The protein-depletion procedure followed by treatment with an alkaline solution to produce SSBs was performed according to Fernández and Gosálvez. ${ }^{15}$

To determine the total DNA damage, a whole-genome DNA probe was produced
Correspondence: Dr. Martha I. DávilaRodríguez,Centro de Investigación Biomédica del Noreste, Instituto Mexicano del Seguro Social, Monterrey, N Nuevo León, C.P. 64720 , Mexico.

Tel. + Fax: +52.81.81904035.

E-mail: marthadavila@cibinmty.net

Funding: This research was supported by the Instituto Mexicano del Seguro Social (FIS/IMSS/PROT/G15/1420) and Fondo Sectorial de Investigación en Salud y Seguridad Social SS/IMSS/ISSTE-CONACYT (293539)

Key words: DNA damage; acute myeloid leukemia; DNA breakage detection-fluorescence in situ hybridization; Mexico.

Received for publication: 14 September 2017. Accepted for publication: 30 November 2017.

This work is licensed under a Creative Commons Attribution-NonCommercial 4.0 International License (CC BY-NC 4.0).

CCopyright M.I. Dávila-Rodriguez et al., 2017 Licensee PAGEPress, Italy

European Journal of Histochemistry 2017; 61:2851 doi:10.4081/ejh.2017.2851

from leukocyte pellets by using a DNA isolation kit for mammalian blood (Roche Diagnostics Co., Indianapolis, IN, USA). The hybridized DNA probe was detected by incubation for $30 \mathrm{~min}$ with fluorescein isothiocyanate-labeled avidin (1:400; Roche Diagnostics Co.). Finally, the slides were counterstained with 4',6-diamidino-2phenylindole (DAPI) (1 $\mathrm{mg} / \mathrm{mL})$ in Vectashield mounting medium (Vector Laboratories, Burlingame, CA, USA).

\section{Comet assay}

To confirm the results obtained with DBD-FISH, the alkaline comet assay was performed using the basic rationale of Singh et al., ${ }^{16}$ with modifications. ${ }^{17}$ The quantification of DNA damage was performed by protein-depletion, treatment with an alkaline solution and SSBs migration in an electric field.

\section{Treatment with $\mathrm{H}_{2} \mathrm{O}_{2}$ (positive control)}

Each experiment included two positive controls; a sample of healthy volunteers and one of AML patient. Slides were exposed to $\mathrm{H}_{2} \mathrm{O}_{2}(20 \mathrm{mM})$, previously to DBD-FISH technique.

\section{Repair experiment in vitro}

PBL from a 37-year-old female who was newly diagnosed with AML were used to 
perform three cultures on RPMI-1640 medium supplemented with fetal calf serum (Gibco-Life Technologies, Waltham, MA, USA): to evaluate DNA damage, cells were treated with mitomycin $\mathrm{C}(0.2 \mathrm{mg} / \mathrm{mL})$ for $48 \mathrm{~h}$; to evaluate DNA repair, cells were treated with mitomycin $\mathrm{C}$ for $72 \mathrm{~h}$; and cells was used as the negative control because it was not treated with any mutagenic agent. All cultures were harvested at $72 \mathrm{~h}$ for processing through the DBD-FISH technique.

The same strategy was applied to a sample of control PBL from an age- and sexmatched healthy individual. Two replicates for each experiment were performed.

\section{Image analysis}

The slides were analyzed using a digital image analysis platform based on a Zeiss Axiophot fluorescence microscope (Carl Zeiss, Göttingen, Germany). The Images were recorded using an Axiocam 16-bit black-andwhite charge-coupled device in a 12-bit TIFF format. The integrated density (ID) values obtained after background subtraction were calculated using Image J 1.4.3.6.7. (http://rsb.info.nih.gov/ij/). For this purpose, ID (area $x$ gray scale) after background subtraction was calculated in pixels (px).$^{18}$ Fifty cells were analyzed for each sample.

\section{Statistical analysis}

Data were entered a database for statistical analysis. All analyses were performed using the package IBM-SPSS for Windows 20.0 (IBM Corp., Armonk, NY, USA). The ID in the four groups studied was transformed using $\log _{10}$. The mean values for transformed data and for not transformed data were analyzed by one-way ANOVA. A $\mathrm{P}$-value less than 0.05 was considered significant. The sample size was estimated using the Minitab software (ver. 15) for one-way ANOVA $(\alpha=0.05,1-\beta=0.80$, corrected sum of the squares of means = 2534102586, and Sigma $=54400.5$ ). A minimum sample size of 13 individual per group was obtained. Significance was set at $\mathrm{P}<0.05$ for all tests
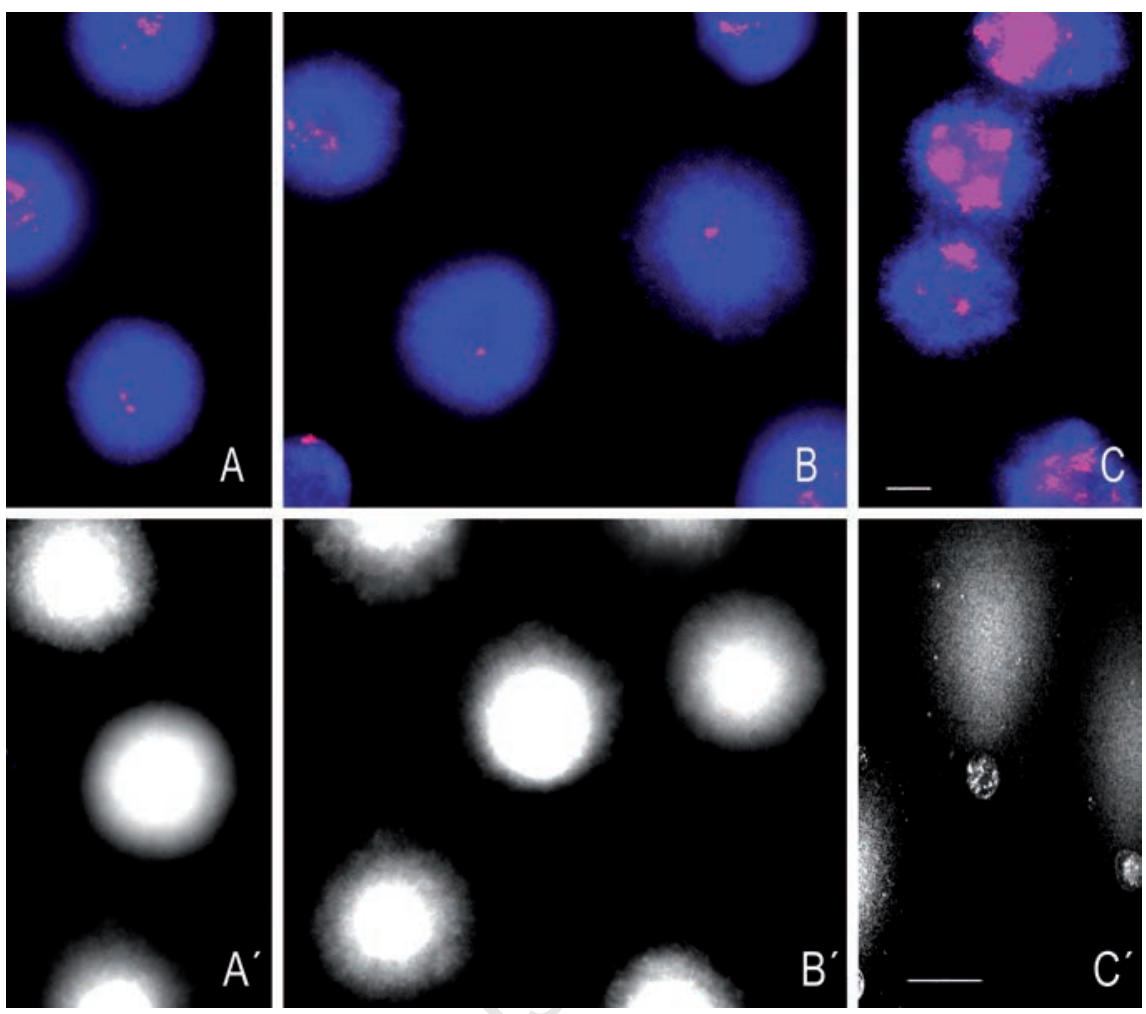

Figure 1. Analysis of DNA damage in peripheral blood leukocytes after DBD-FISH using whole probe labeled with biotin (red) and counterstained with DAPI (blue). A) Healthy individual; B) patient with AML; C) positive control healthy $\left(\mathrm{H}_{2} \mathrm{O}_{2}\right)$. Analysis by comet assay (Comet tail $\left.\mu \mathrm{m}): A^{\prime}\right) 42.7 \pm 6.1$; B') $47.4 \pm 8.3$; C') $130 \pm 11.8$. Scale bars: A-C) $5 \mu \mathrm{m}$; A'-C') $10 \mu \mathrm{m}$.

Table 1. Integrated density values in peripheral blood leukocytes of acute myeloid leukemia patients after DBD-FISH using probe whole genome.

\begin{tabular}{lccc} 
Group & n & \multicolumn{2}{c}{ Fluorescence analysis } \\
Healthy (A) & 13 & $18.99 \pm 4.39^{3,4}$ & $4.17 \pm 0.93^{3,4}$ \\
AML (B) & 22 & $17.34 \pm 3.83^{3,4}$ & $4.08 \pm 0.09^{3,4}$ \\
\hline Positive control-healthy (C) & 13 & $79.37 \pm 24.97^{1,2}$ & $4.63 \pm 0.14^{1,2}$ \\
Positive control-AML (D) & 22 & $126.71 \pm 28.49^{1,2}$ & $4.71 \pm 0.16^{1,2}$ \\
\hline
\end{tabular}

ID, integrated density; *average \pm SE values represent 103 ; anot transformed ID values; btransformed ID values; AML, acute myeloid leukemia; Test ANOVA: ${ }^{1}$ different from group $\mathrm{A}, \mathrm{P}<0.05 ;{ }^{2}$ different from group $\mathrm{B}, \mathrm{P}<0.05 ;{ }^{3}$ different from group $\mathrm{C}, \mathrm{P}<0.05 ;{ }^{4}$ different from group $\mathrm{D}, \mathrm{P}<0.05$

Table 2. Experiments for evaluate DNA damage/reparation by DBD-FISH in peripheral blood leukocytes cultures of a patients with acute myeloid leukemia and a healthy individual after exposition at mitomycin-C.

\begin{tabular}{|c|c|c|c|c|c|c|}
\hline \multirow[b]{2}{*}{ Time } & \multicolumn{3}{|c|}{ Acute myeloid leukemia sample } & \multicolumn{3}{|c|}{ Healthy sample } \\
\hline & Control & Damage & Reparation & Control & Damage & Reparation \\
\hline T0 & & & MMC & & & MMC \\
\hline $24 \mathrm{~h}$ & & MMC & & & MMC & \\
\hline $72 \mathrm{~h}$ & Harvest & Harvest & Harvest & Harvest & Harvest & Harvest \\
\hline ID & 18.39 & 287.13 & 60.05 & 16.48 & 123.80 & 30.80 \\
\hline
\end{tabular}

Time, time of culture; damage, culture with exposition to mitomycin-C for $48 \mathrm{~h}$ for evaluating DNA damage; reparation, culture with exposition to mitomycin-C for $72 \mathrm{~h}$ for evaluating DNA damage; control, represent DNA damage and reparation levels in a culture without the exposition mutagenic agent; ID, integrated density average value in pixels; MMC, mitomycin-C. 


\section{Results}

The average age was similar among the groups $(\mathrm{P}>0.05)$. Cells that were treated with hydrogen peroxide exhibited elevated ID values, which confirmed the accessibility of the cells to the tested chemicals (Figure 1C). Conversely, cells without treatment showed a slight fluorescent signal that corresponded to the basal or constitutive damage for this type of cells (Figure 1A). Patients with AML demonstrated similar results to the negative control group (Figure 1). The results presented above were confirmed by the comet assay (Figure 1A'-C').

The analysis of the ID in the group of patients with AML (Figure 1B) yielded results that were similar $(\mathrm{P}>0.05)$ to those obtained for the control group (Figure 1A). Leukocytes of positive controls (treated with $\mathrm{H}_{2} \mathrm{O}_{2}$ ) of healthy and AML, showed a significant increase in ID compared with the group of AML patients and healthy group $(\mathrm{P}<0.05)$ (Table 1$)$.

The repair experiment performed on leukocytes from a patient with AML showed an ID value that suggest a sensitivity higher to damage (287.13 px) than control cells (123.8 px) and repair efficiency similar in the two groups of cells $(21 \%$ and $24 \%$, respectively). Finally, ID values of AML and healthy control were similar (Table 2).

\section{Discussion}

Our results demonstrated that the DNA damage detected in patients with newly diagnosed AML was similar to that observed for the controls. Previous studies of DNA damage in patients with newly diagnosed leukemia $v s$ controls used in vitro techniques, such as $\mathrm{SCE}^{8-10,19}$ and the $\mathrm{MN}^{6,7}$ tests showed findings contradictory. To our knowledge, only a study of DNA damage ex vivo in PBL of patients with newly diagnosed leukemia vs controls used the alkaline comet assay to determinate DNA damage in patients with AML from Cairo, Egypt, showed that the tail moment was significantly higher in patients compared with the control group. ${ }^{13}$ This result disagrees with our findings from Mexican patients, ethnic differences could be one of the causes underlie this discrepancy. ${ }^{20,21}$

Our results may be attributed to repairinduced DNA lesions. This capacity to repair was reported previously by Müller $e t$ al. ${ }^{22}$ for lymphocytes from patients with Chronic lymphocytic leukemia who were nonresponsive to alkylating agents. Those cells exhibited faster processing repairinduced SSBs compared with control cells, which could be explained by the presence of cytotoxic DNA lesions induced by the alkylating agents. Recently, Portich et al. ${ }^{14}$ assessed DNA damage in pediatric patients with acute lymphoid leukemia using the comet assay and found no increase in damage during induction therapy (diagnosis, 15 days, and 35 days), which suggests that this repair pathway may be stimulated in the following scenarios: i) as a tumor response; ii) as a defense from chemotherapy; or iii) both (pathogenesis of the disease and chemotherapy).

Our findings support the first scenario because we did not find increased damage in patients with newly diagnosed AML compared with the control group. In addition, the repair experiment performed on leukocytes from a patient with AML are indicative that the sensitivity to damage in cells from the patients was greater that of the control cells, and the percentage of repair was similar in the two groups.

To confirm our findings, it will be necessary to perform studies using DBD-FISH with probes for specific chromosomal regions ${ }^{8,23}$ with significance in leukemogenesis or for genes involved in DNA damage and repair, which have been identified in AML patients. . $^{5,24-26}$ This information may be useful for the measurement of cellular interindividual heterogeneity ${ }^{3}$ and to perform associations with sensitivity to the pathology itself or to chemotherapy. ${ }^{24,26}$

In conclusion, in this study preliminary we reported absence of an increase in DNA damage in patients with newly diagnosed AML compared with controls and suggested that this may be explained by the stimulation of a repair pathway by the pathogenesis itself. Future studies are needed to confirm our findings

\section{References}

1. Estey E, Dohner H. Acute myeloid leukaemia. Lancet 2006;368:1894-907.

2. Döhner H, Estey EH, Amadori S, Appelbaum FR, Büchner T, Burnett $\mathrm{AK}$, et al. Diagnosis and management of acute myeloid leukemia in adults: recommendations from an international expert panel, on behalf of the European LeukemiaNet. Blood 2010;115:453-74.

3. Mosna F, Capelli D, Gottardi M. Minimal residual disease in acute myeloid leukemia: Still a work in progress? J Clin Med 2017;6:pii: E57

4. Grimwade D, Walker H, Oliver F, Wheatley K, Harrison C, Harrison G, et al. The importance of diagnostic cytogenetics on outcome in AML: analysis of 1,612 patients entered into the MRC AML 10 trial. The Medical Research Council Adult and Children's Leukaemia Working Parties. Blood 1998;92:2322-33.

5. Esposito MT, So CW. DNA damage accumulation and repair defects in acute myeloid leukemia: implications for pathogenesis, disease progression, and chemotherapy resistance. Chromosoma 2014;123:545-61.

6. Hamurcu Z, Dönmez-Altuntas H, Patiroglu T. Basal level micronucleus frequency in stimulated lymphocytes of untreated patients with leukemia. Cancer Genet Cytogenet 2008;180:1404.

7. Wang RC, Yang L, Tang Y, Bai O. Micronucleus expression and acute leukemia prognosis. Asian Pac J Cancer Prev 2013;14:5257- 61.

8. Larripa I, Labal de Vinuesa M, Slavutsky I, Brieux de Salum S. Sister chromatid exchanges in leukemic patients. Cancer Genet Cytogenet 1985; $15: 169 \mathrm{e} 75$.

9. Becher R, Zimmer G, Schmidt CG. Sister chromatid exchange and growth kinetics in untreated acute leukemia. Int J Cancer 1981;27:199-204.

10. Becher R, Zimmer G, Schmidt CG, Sandberg AA. Sister chromatid exchange in normal and Ph1-positive leukemic cells after mitomycin-C treatment in vitro. Cancer Genet Cytogenet 1984;12:239-45.

11. Becher R, Prescher G. Induction of sister chromatid exchanges and chromosomal aberrations by busulfan in Philadelphia chromosomepositivechronic myeloid leukemia and normal bone marrow. Cancer Res 1988; 48:3435-9.

12. Tuna M, Artan S, Gezer S, Sxayli BS, Basxaran N. Sister chromatid exchange analysis in acute leukemia patients. Cancer Genet Cytogenet 1995;79:86-8.

13. Kamal AM, El-Hefny NH, Hegab HM, El-Mesallamy HO. Expression of thioredoxin-1 (TXN) and its relation with oxidative DNA damage and treatment outcome in adult AML and ALL: A comparative study. Hematology 2016;21:567-75.

14. Portich JP, Dos Santos RP, Kersting N, Jorge KB, Casagrande PR, Dos Santos Costa $\mathrm{G}$, et al. DNA damage response in patients with pediatric Acute Lymphoid Leukemia during induction therapy. Leuk Res 2017;54:59-65.

15. Fernández JL, Gosálvez J. Application 
of FISH to detect DNA damage: DNA breakage detection-FISH (DBD-FISH). Methods Mol Biol 2002;203:203-16.

16. Singh NP, Mc Coym MT, Tice RR, Schneider EL. A simple technique for quantitation of low levels of DNA damage in individual cells. Exp Cell Res 1988;175:184-91.

17. Cortés-Gutiérrez EI, Dávila-Rodríguez MI, Cerda-Flores R, Fernández JL, López-Fernández C, Aragón Tovar A, et al Localization and quantification of alkali-labile sites in human spermatozoa by DBD-FISH. Andrologia 2015;47: 221-7.

18. Rasband WS. ImageJ, U. S. National Institutes of Health, Bethesda, MD, USA; 1997-2006.

19. Jones BM, White AD, Culligan DJ, Jacobs A. Cell-cycle progression rates and sister chromatid exchange frequencies in the bone marrow of patients with myelodysplastic syndrome and acute myeloid leukemia. Cancer Genet
Cytogenet 1992;62:66-9.

20. Malik E, Cohen SB, Sahar D, Dann EJ, Rund D. The frequencies of $\mathrm{NAD}(\mathrm{P}) \mathrm{H}$ quinone oxidoreductase (NQO1) variant allele in Israeli ethnic groups and the relationship of $\mathrm{NQO} 1 * 2$ to adult acute myeloid leukemia in Israeli patients. Haematologica 2006;91:9569.

21. Ghazaey ZS, Hosseinzaeh CA Geographic heterogeneity of the AML1-ETO fusion gene in Iranian patients with acute myeloid leukemia. Rep Biochem Mol Biol 2014;3:7-13.

22. Müller MR, Buschfort C, Thomale J, Lensing C, Rajewsky MF, Seeber S. DNA repair and cellular resistance to alkylating agents in chronic lymphocytic leukemia. Clin Cancer Res 1997;3: 2055-61.

23. Escobar PA, Smith MT, Vasishta A, Hubbard AE, Zhang L. Leukaemia-specific chromosome damage detected by comet with fluorescence in situ hybridization (comet-FISH). Mutagenesis 2007;22:321-7.

24. Seedhouse CH, Hunter HM, LloydLewis B, Massip A-M, Pallis M, Carter GI, et al. DNA repair contributes to the drug-resistant phenotype of primary acute myeloid leukaemia cells with FLT3 internal tandem duplications and is reversed by the FLT3 inhibitor PKC412. Leukemia 2006; 20:2130-6.

25. Rebechi MT, Pratz KW. Genomic instability is a principle pathologic feature of FLT3 ITD kinase activity in acute myeloid leukemia leading to clonal evolution and disease progression. Leuk Lymphoma 2017;58:1-11.

26. Cagnetta A, Soncini D, Orecchioni S, Talarico G, Minetto P, Guolo F, et al. Depletion of SIRT6 enzymatic activity increases acute myeloid leukemia cells vulnerability to DNA-damaging agents. Haematologica 2017; doi: 10.3324/ haematol.2017.176248. [Epub 2017 Oct $12]$. 